\title{
Ethylene-mediated signaling confers thermotolerance and regulates transcript levels of heat shock factors in rice seedlings under heat stress
}

\author{
Yu-Sian Wu and Chin-Ying Yang ${ }^{*}$
}

\begin{abstract}
Background: Agriculture is highly dependent on climate. Increases in temperature caused by global warming pose challenges for crop production. Heat stress induces oxidative damage to cell membranes and then causes cell death. Plants have developed various responses to elevated temperatures, including hormone signaling pathways and heat shock factors that elevate their thermotolerance. In response to heat stress, the gaseous hormone ethylene is produced through regulation of the expression of signaling-related genes to modulate resource allocation dynamics. For comprehensive understanding of the role of ethylene, this study used an ethylene precursor to analyze the ethylene signaling pathway involved in adjustment of the homeostasis of the antioxidant system and to evaluate heat shock factor expression in rice seedlings under heat stress.

Results: Levels of cell membrane oxidation and ion leakage were reduced in rice seedlings under heat treatment combined with ethylene precursor treatment, conferring enhanced thermotolerance. Reduction of the fresh weight and chlorophyll a/b ratio in rice seedlings was lower in rice seedlings under heat stress with ethylene precursor treatment than in those under heat stress only. Moreover, reduction of antioxidant response caused by heat stress was ameliorated by treatment with ethylene precursors such as catalase and total peroxidase. Quantitative reverse transcriptase-polymerase chain reaction showed higher expression levels of heat shock factors such as HSFA1 a and HSFA2a, $c, d, e$, and $f$ and ethylene-signaling-related genes such as ethylene insensitive 2, ethylene insensitive-like 1 , and ethylene insensitive-like 2 in rice seedlings under heat stress with ethylene precursor treatment than in rice seedlings under heat stress only.
\end{abstract}

Conclusion: Ethylene-mediated signaling was involved in the reduction of oxidative damage, maintenance of chlorophyll content, and enhancement of thermotolerance in rice seedlings under heat stress. Furthermore, this study revealed heat shock factors and ethylene-signaling-related genes involved in complex network regulation that confers thermotolerance to rice seedlings.

Keywords: Heat stress, Ethylene, Heat shock factor, Thermotolerance, Antioxidant enzyme

${ }^{*}$ Correspondence: emiyang@dragon.nchu.edu.tw

Department of Agronomy, National Chung Hsing University,

Taichung 40227, Taiwan 


\section{Background}

Due to climate change and rising global temperatures, crops are frequently exposed to heat stress, which subsequently threatens food security. Heat stress affects crop growth, photosynthesis, and membrane stability and reduces financial yield (Kotak et al. 2007; Schauberger et al. 2017; Wahid et al. 2007). To adapt to high-temperature conditions, plants have evolved two mechanisms to face environmental pressure. One mechanism is intrinsic thermotolerance; plants have the inherent ability to survive under temperatures higher than the optimal temperature for growth. The other mechanism is acquired thermotolerance; plants have the ability to grow under lethally high temperatures following acclimatization to such temperatures over a short period (Liu and Charng 2012; Song et al. 2012). Studies have indicated that survival rates are enhanced by exposing rice, maize, barley, and Arabidopsis plants to extreme temperatures for short periods and allowing subsequent recovery (Charng et al. 2007; Hong and Vierling 2000; Maestri et al. 2002; Queitsch et al. 2000).

The plant hormone ethylene is reportedly a key regulator involved in abiotic or biotic stress signaling. Interaction between ethylene and a receptor complex triggers inactivation of constitutive triple response 1 kinase, which leads initially to dephosphorylation of ethylene insensitive 2 (Savada et al. 2017) by an as-yetunidentified phosphatase and subsequently to cleavage of the C-terminal of EIN2 and its translocation to the nucleus, where it regulates EIN3/EIL1 activation. EIN3/ EIL1 proteins further regulate ethylene response factors (ERFs) (Yoshida et al. 2011) and promote the transcriptional cascade that activates and represses hundreds of genes under the ethylene signaling pathway (Müller and Munné-Bosch 2015). The survival rates of ethylene receptor 1 and EIN2 mutants were lower than those of wildtype Arabidopsis under heat stress; this finding supported that ethylene signaling is involved in the basal thermotolerance mechanism (Larkindale and Knight 2002; Larkindale et al. 2005).

Heat stress transcription factors (HSFs) - which comprise the plant intracellular response to heat stress-bind to the promoter element of heat shock proteins, which function as molecular chaperones that prevent aggregation of proteins and facilitate refolding of heat-damaged proteins. The gene diversity of HSF families has been identified as 21 in Arabidopsis, 25 in rice (Oryza sativa), 30 in maize (Zea mays), and 24 in millet (Guo et al. 2008, 2016; Scharf et al. 2012). According to HSF protein structure characterization and phylogenetic analysis, HSFs can be categorized into classes A-C (von Koskull-Döring et al. 2007). Recent studies on Arabidopsis have supported that heat shock factor A1 (HsfA1), as a critical regulator, activates heat stress response signaling (Liu and Charng 2013; Ohama et al. 2017; Shi et al. 2015). In Arabidopsis, the messenger RNA (mRNA) accumulation levels of heat shock proteins in HSFA1a/b double mutants and $H S F A 1 a / b / d / e$ quadruple mutants were lower than the corresponding levels in wild-type under heat shock conditions. These results indicated that HsfA1 activates the heat stress transcription network in the early stage of the heat response (Lohmann et al. 2004; Yoshida et al. 2011). The mRNA transcript level of HSFA2 target genes such as heat shock proteins 70 and 90 was downregulated in hsfa2-knockout mutants under heat stress (Schramm et al. 2006). The hsfa2-knockout Arabidopsis mutant was sensitive to high temperatures and exhibited decreased hypocotyl growth under prolonged heat stress and recovery (Charng et al. 2007). Overexpression of the transcript of OsHsfA2e (LOC_Os03g58160) increased the survival rate of Arabidopsis plants after heat stress (Yokotani et al. 2008). Microarray analysis revealed that the expression levels of OsHsfA2a, $d$, and $e$ were higher in rice seedlings under treatment heat stress than in controls (Chauhan et al. 2011).

Recent research has discovered that ethylene signaling is involved in the heat stress response pathway. ERF1overexpressing Arabidopsis exhibited greater tolerance than did controls under heat shock treatment. Microarray analysis revealed that the transcript levels of $H s f A 3$ and HSP7O were upregulated in ERF1-overexpression line under heat shock treatment. These results supported that ERF1 can recognize the GCC box element on the promoter of $H s f A 3$ and $H S P 70$ and can enhance thermotolerance in Arabidopsis (Cheng et al. 2013).

Limited information is available on the ethylene signaling regulatory mechanism under heat stress. In the current study, our results showed that the levels of cell membrane oxidation and ion leakage were reduced in rice seedlings under heat treatment combined with ethylene precursor treatment, thereby conferring enhanced thermotolerance. The transcript levels of HsfAla and $A 2 a, c, d, e$, and $f$ genes were higher under heat treatment combined with ethylene precursor treatment than under heat stress only. Furthermore, the transcript levels of ethylene-signaling-related genes were higher under heat treatment combined with ethylene precursor treatment than under heat stress only. These results supported that ethylene signaling is involved in the complex regulation of $H s f$ gene expression during heat stress.

\section{Methods}

\section{Plant materials and treatments}

Oryza sativa L. japonica cv. Taikeng No. 9 was used in this study. We used 3\% sodium hypochlorite to sterilize the seed surface for $40 \mathrm{~min}$, and the seeds were then 
washed with sterile deionized water several times to remove the buffer added for seed sterilization. The seeds were placed on filter paper for 3 days and germinated in a growth chamber at $28{ }^{\circ} \mathrm{C}$ under 16 -h light and at $23^{\circ} \mathrm{C}$ under 8-h darkness. The germinated seeds were planted on a metal grid over a $500 \mathrm{~mL}$ beaker containing Kimura B solution (Yoshida et al. 1976). A total of 30 germinated seeds were placed in each beaker and the culture solution was changed every 2 days for 12 days. For high-temperature treatment were modified from research in rice (Fang et al. 2015; Mangrauthia et al. 2017), 12-day-old seedlings were placed in a growth chamber at $45{ }^{\circ} \mathrm{C}$ under a 16:8-h light:dark cycle, and the relative humidity at $50 \%$ for 4 days. For the high temperature combined with ACC treatment, 12-day-old seedlings were treated with $10 \mu \mathrm{M}$ ACC at $45{ }^{\circ} \mathrm{C}$. Control plants remained in the growth chamber at $28{ }^{\circ} \mathrm{C}$ under 16 -h light and $23{ }^{\circ} \mathrm{C}$ under 8 -h darkness. After each treatment, shoot samples were collected from rice seedlings, immediately frozen in liquid nitrogen, and stored at $-80{ }^{\circ} \mathrm{C}$ until analysis. Independent experiments with 30 seedlings were conducted and each experiment was repeated at least three times.

\section{Measurement of fresh weight, survival rate, lipid peroxidation, and ion leakage in rice seedlings}

To measure the fresh weight, we collected the shoot of rice seedling and detected the weight per plant after heat stress treatment with or without ACC for 4 days. Independent experiments with 10 seedlings were conducted and each experiment was repeated at least three times. To evaluate the survival rate, growth of new leaves in rice seedlings was allowed after heat treatment with or without $10 \mu \mathrm{M}$ ACC for 4 days, with recovery for 7 days. The lipid peroxidation assay was conducted according to a modification of the method of Jambunathan (2010). After each treatment, the shoot of rice seedlings was collected $0.2 \mathrm{~g}$ fresh weight, homogenized in $4 \mathrm{~mL}$ of $5 \%$ trichloroacetic acid (TCA), and centrifuged at 10,000 $\times g$ for $5 \mathrm{~min}$. After centrifugation, $1 \mathrm{~mL}$ supernatant was collected and mixed with $4 \mathrm{~mL}$ thiobarbituric acid (TBA) solution containing $0.5 \% \mathrm{TCA}$ and 20\% TBA. The reaction mixture was heated to $95{ }^{\circ} \mathrm{C}$ for $30 \mathrm{~min}$ and placed on ice to halt the reaction. Absorbance of the supernatant was detected at 532 and $600 \mathrm{~nm}$ on a spectrophotometer (Metertec SP8001, Taipei, Taiwan, R.O.C). The percentage of ion leakage was determined according to the method of Jambunathan (2010) with some modifications. Five leaves of rice seedlings were collected in a $15-\mathrm{mL}$ centrifuge tube with deionized water and incubated at $25^{\circ} \mathrm{C}$ for $3 \mathrm{~h}$. After incubation, the conductivity of the bathing solutions of each treatment $\left(C_{1}\right)$ and deionized water $\left(C_{1}{ }^{\prime}\right)$, which was used as the background solution, was determined using an electrical conductivity meter. The bathing solutions of each treatment and deionized water were boiled for $30 \mathrm{~min}$ and the conductivity of the bathing solutions of each treatment $\left(C_{2}\right)$ and deionized water $\left(C_{2}{ }^{\prime}\right)$ was determined to calculate the percentage of ion leakage as follows: ion leakage $(\%)=\left(C_{1}-C_{1}{ }^{\prime}\right) /\left(C_{2}-C_{2}{ }^{\prime}\right) \times 100 \%$.

\section{Measurement of chlorophyll concentration in rice seedlings}

After each treatment, the shoot of rice seedlings was collected and extracted from $50 \mathrm{mg}$ of leaf tissue in $2 \mathrm{~mL}$ of $50 \mathrm{mM}$ sodium phosphate buffer ( $\mathrm{pH}$ 6.8). Then taken $40 \mu \mathrm{L}$ extraction buffer added into $960 \mu \mathrm{L}$ of $99 \%$ ethanol mix together; the mixture was vortexed thoroughly and incubated for $30 \mathrm{~min}$ at $4{ }^{\circ} \mathrm{C}$ in darkness. After centrifugation at $4{ }^{\circ} \mathrm{C}$ for $15 \mathrm{~min}$ at $1000 \times g$, the supernatant was collected. Absorbance of the supernatant was measured at 665 and $649 \mathrm{~nm}$ on the spectrophotometer (Metertec SP8001, Taipei, Taiwan, R.O.C).

\section{Assay of $\mathrm{H}_{2} \mathrm{O}_{2}$ accumulation and cell viability by histochemical staining method}

Accumulation of $\mathrm{H}_{2} \mathrm{O}_{2}$ in cell was visualized by the 3, 3'-diaminobenzidine (DAB) staining method. 12-day old seedlings after heat stress with or without $10 \mu \mathrm{M}$ ACC treatment for 4 days, the 3rd leaves were immersed into DAB solution prepared in at RT under dark for $12 \mathrm{~h}$. When brown spots or pattern appeared, we used $75 \%$ ethanol and boiled leaves until the pigments were removed from leaves. Cell viability assay was visualized by the Evans blue staining. 12-day old seedlings after heat stress with or without $10 \mu \mathrm{M}$ ACC treatment for 4 days, and collected the 3rd leaves. To weigh and immerse the leaves into $0.2 \%$ Evans blue solution for $12 \mathrm{~h}$. When blue spots or pattern appeared, we used $75 \%$ ethanol and boiled leaves until the pigments were removed from leaves. Experiments were repeated three times independently.

\section{Antioxidant enzyme activity assays}

For antioxidant enzyme assays, 12-day-old seedlings were treated with heat stress $\left(45^{\circ} \mathrm{C}\right)$ with or without $10 \mu \mathrm{M}$ ACC for 4 days and their shoots were collected for analysis. Shoot tissue $(150 \mathrm{mg})$ was homogenized in liquid nitrogen and immediately used for enzyme extraction. The protein concentration of each extract from samples was determined by Bradford protein assay (Bradford 1976). Antioxidant enzyme assay was used $1 \mathrm{mg}$ protein of each extract samples, subsequently. Activity levels of CAT, APX, SOD, and POX were analyzed as previously described (Wu and Yang 2016). In the CAT assay, the decrease in the hydrogen peroxide level was monitored by measuring absorbance at $240 \mathrm{~nm}$ for $1 \mathrm{~min}$. Sodium phosphate buffer (50 mM; pH 6.8) was used to extract 
samples, which were then centrifuged at $12,000 \times g$ for $20 \mathrm{~min}$. The reaction mixture consisted of $100 \mathrm{mM}$ potassium phosphate buffer ( $\mathrm{pH}$ 7.0), $1 \mathrm{M} \mathrm{H}_{2} \mathrm{O}_{2}$, and supernatant of the extracted enzyme. $\mathrm{H}_{2} \mathrm{O}_{2}$ was added to initiate the reaction, which was recorded for $1 \mathrm{~min}$. One unit of CAT activity was defined as consumption of $1 \mathrm{nmol} \mathrm{H}_{2} \mathrm{O}_{2}$ per minute. In the APX assay, a decrease in absorbance due to ascorbic acid was recorded at $290 \mathrm{~nm}$ (Nakano and Asada 1981). The reaction mixture consisted of $150 \mathrm{mM}$ potassium phosphate buffer ( $\mathrm{pH} 7.0$ ), $1.5 \mathrm{mM}$ ascorbic acid, $0.75 \mathrm{mM}$ ethylenediaminetetraacetic acid (EDTA), $6 \mathrm{mM} \mathrm{H} \mathrm{H}_{2}$, and supernatant of the extracted enzyme. The decrease in absorbance was measured at $290 \mathrm{~nm}$ for $1 \mathrm{~min}$. One unit of APX activity was defined as consumption of $1 \mu \mathrm{mol}$ ascorbic acid per minute. In the SOD assay, suppression of the oxidation rate of $\beta$-nicotinamide adenine dinucleotide ( $\beta$-NADH) to $50 \%$ was monitored by measuring absorbance at $340 \mathrm{~nm}$ for $10 \mathrm{~min}$. Sodium phosphate buffer $(50 \mathrm{mM}$; $\mathrm{pH}$ 7.4) was used to extract samples, which were then centrifuged at $15,000 \times g$ for $30 \mathrm{~min}$. The reaction mixture consisted of $100 \mathrm{mM}$ triethanolamine-diethanolamine buffer (pH 7.4), $100 \mathrm{mM} / 50 \mathrm{mM}$ EDTA/ $/ \mathrm{MnCl}_{2}(\mathrm{pH}$ 7.4), $7.5 \mathrm{mM} \beta$-NADH, $10 \mathrm{mM}$ 2-mercaptoethanol, and supernatant of the extracted enzyme. In the POX assay, production of tetraguaiacol was monitored by measuring absorbance at $470 \mathrm{~nm}$ for $1 \mathrm{~min}$. Potassium phosphate buffer (50 mM; pH 5.8) containing $0.8 \mathrm{M} \mathrm{KCl}$ was used to extract samples, which were then centrifuged at $12,000 \times g$ for $20 \mathrm{~min}$. The reaction mixture consisted of $50 \mathrm{mM}$ potassium phosphate buffer ( $\mathrm{pH} 5.8$ ), $21.6 \mathrm{mM}$ guaiacol, $39 \mathrm{mM} \mathrm{H}_{2} \mathrm{O}_{2}$, and supernatant of the extracted enzyme.

\section{Quantitative RT-PCR analyses}

Total RNA was extracted from frozen rice shoots in each treatment by using the TRI reagent (Invitrogen) and the RNA pellet was washed with ice-cold $75 \%$ ethanol, air dried, and dissolved in $30 \mu \mathrm{L}$ diethyl pyrocarbonate water. To prevent DNA contamination, all DNA was removed from the samples by using the TURBO DNA-free Kit (Ambion, Austin, TX, USA). RNA concentration was determined spectrophotometrically and the 260/280-nm absorbance ratio showed expected values between 1.8 and 2.0. Total RNA $(2 \mu \mathrm{g})$ was reverse transcribed into cDNA by using Moloney murine leukemia virus reverse transcriptase (Invitrogen). Quantitative RT-PCR was performed on a Bio-Rad instrument (CFX Connect ${ }^{\mathrm{TM}}$, USA) with SYBR Green dye (Invitrogen) in accordance with the manufacturer's recommendations. The ubiquitin gene (Os03g13170) was used as an internal control to normalize cDNA levels. The amplification conditions were as follows: $94{ }^{\circ} \mathrm{C}$ for $5 \mathrm{~min}$, and then 45 cycles at $94{ }^{\circ} \mathrm{C}$ for
$30 \mathrm{~s}, 55^{\circ} \mathrm{C}$ for $30 \mathrm{~s}$ and $72{ }^{\circ} \mathrm{C}$ for $30 \mathrm{~s}$. The relative expression levels were analyzed using the $2-\Delta \Delta \mathrm{Ct}$ method with Bio-Rad software. Experiments were repeated six times independently and performed in duplicate. The primer sequences used for quantitative RT-PCR analyses are listed in Additional file 1: Table S1.

\section{Results \\ Ethylene-mediated signaling reduced oxidative damage in rice seedlings under heat stress}

To determine the effect of ethylene signaling during heat stress, 12-day-old rice seedlings were grown in Kimura $B$ medium with or without supplementation of ethylene precursor 1-aminocyclopropane-1-carboxylic acid (ACC) and were subsequently subjected to heat stress $\left(45^{\circ} \mathrm{C}\right)$ treatment for 4 days. Regarding their phenotype, rice seedlings under heat stress presented more green leaves after $10 \mu \mathrm{M}$ ACC treatment (Fig. 1a). Compared with the controls, the fresh weight of rice seedlings showed $63 \%$ and $38 \%$ reduction after heat stress with 0 and $10 \mu \mathrm{M}$ ACC treatment for 4 days, respectively (Fig. 1b). Furthermore, we detected the content of malondialdehyde (MDA) as a cell membrane damage indicator. Compared with the control, the MDA content increased 4.5 times under heat stress for 4 days. Compared with the control, the MDA content increased only 1.5 times under heat stress with $10 \mu \mathrm{M}$ ACC treatment for 4 days (Fig. 1c). Compared with the control, ion leakage was $50 \%$ and $7 \%$ under heat stress without and with ACC, respectively (Fig. 1d). These results indicated that ethylene-mediated signaling is involved in maintaining water content and significantly reducing intracellular lipid peroxidation in rice seedlings under heat stress.

\section{Thermotolerance and chlorophyll content were enhanced in rice seedlings under heat stress and ethylene precursor treatment}

To investigate whether ethylene-mediated signaling affected the seedlings' tolerance to heat stress, 12-day-old rice seedlings were treated with heat stress with or without ACC for 4 days followed by recovery for 7 days for the survival assay. The survival rates of the rice seedlings were $3.84 \%$ and $94.25 \%$ when treated with heat stress without or with $10 \mu \mathrm{M}$ ACC treatment, respectively (Fig. 2).

Chlorophyll is a light-harvesting complex that converts sunlight into chemical energy in a process known as photosynthesis (Bricaud et al. 1995). This study investigated the effect of the ethylene precursor on chlorophyll content in rice seedlings under heat stress with or without $10 \mu \mathrm{M}$ ACC treatment for 4 days. The results showed that the chlorophyll concentration decreased significantly in rice seedlings under heat stress with $0 \mu \mathrm{M}$ ACC 

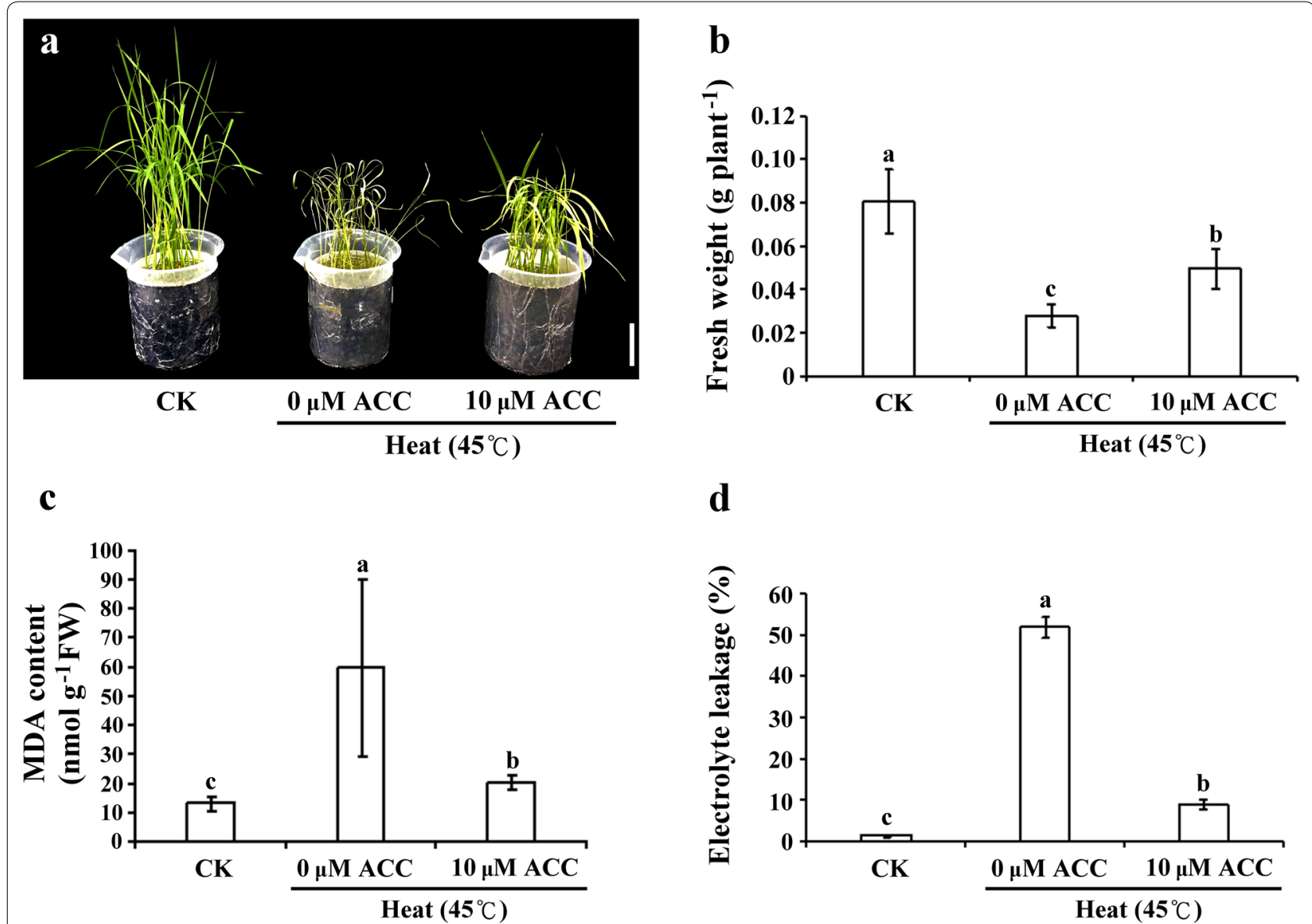

Fig. 1 Effects of heat stress with ACC treatment on phenotype and physiological properties of rice seedlings. a Phenotypes of 12-day-old rice seedlings exposed to heat treatment at $45^{\circ} \mathrm{C}$ with or without $10 \mu \mathrm{M} \mathrm{ACC}$ for 4 days. The same results were observed for three independent experiments. Bar $=5 \mathrm{~cm}$. Fresh weight (b), malondialdehyde (MDA) content (c), and electrolyte leakage $(\mathbf{d})$ in rice seedlings exposed to heat treatment at $45^{\circ} \mathrm{C}$ with or without $10 \mu \mathrm{M} \mathrm{ACC}$ for 4 days. Control check (CK). Values are presented as mean \pm standard deviation based on 30 seedlings of each treatment obtained from three biologically independent experiments. Different letters indicate significant difference between the treatments assessed using the LSD post hoc test $(P<0.05)$

treatment compared with seedlings under heat stress with $10 \mu \mathrm{M}$ ACC treatment. No significant difference was observed in chlorophyll b or total content between $0 \mu \mathrm{M}$ ACC and $10 \mu \mathrm{M}$ ACC treated seedlings under heat stress (Table 1). Additionally, the chlorophyll a/b ratio decreased significantly in the $0 \mu \mathrm{M}$ ACC treated rice seedlings compared with the $10 \mu \mathrm{M}$ ACC treated rice seedlings under heat stress. These results indicated that ethylene-mediated signaling is involved in maintaining chlorophyll content and further enhances thermotolerance in rice seedlings under heat stress.

\section{Reduction of the antioxidant response caused by heat} stress was ameliorated by ethylene precursor treatment in rice seedlings

Many studies have demonstrated that reactive oxygen species (Choudhury et al. 2017) cause plant cell oxidation under abiotic stress. The cellular scavenging capacity of antioxidant enzymes is important to the metabolism of ROS in sorghum, maize, and wheat plants under heat stress (Djanaguiraman et al. 2010; Sairam et al. 2002; Zhu et al. 2010). We investigate the $\mathrm{H}_{2} \mathrm{O}_{2}$ accumulation by DAB staining and cell viability by evens blue staining in rice seedlings under heat stress with or without ACC treatment. The results of DAB staining showed more $\mathrm{H}_{2} \mathrm{O}_{2}$ accumulation pattern in the leave blades under $0 \mu \mathrm{M}$ ACC treatment compared with $10 \mu \mathrm{M}$ ACC treatments under heat stress. In the evans blue staining, the results showed significant accumulation pattern in the leave tip and blade under $0 \mu \mathrm{M}$ ACC treatment compared with $10 \mu \mathrm{M}$ ACC treatment (Fig. 3a). Under heat stress, our data displayed less ROS accumulation and cell damage in rice seedling by ethylene signaling. In the present study, to evaluate the effect of ethylene precursor 


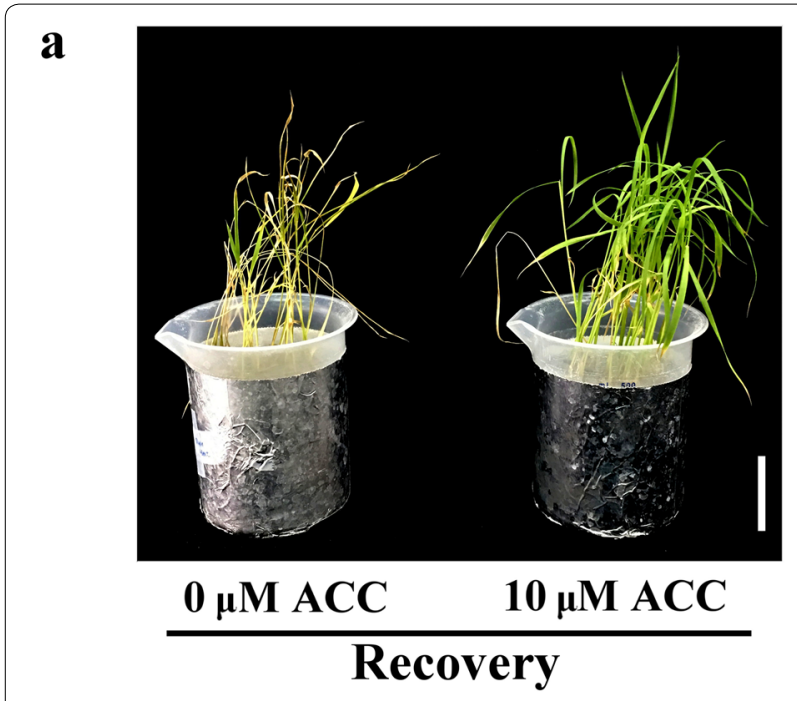

b

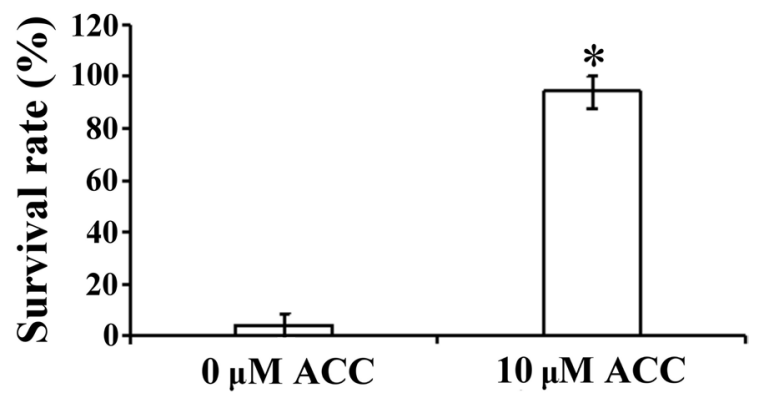

Fig. 2 Tolerance determination of rice seedlings under heat stress combined with ACC treatment. a Phenotypes of 12-day-old TK9 rice seedlings exposed to $45^{\circ} \mathrm{C}$ heat treatment with or without $10 \mu \mathrm{M}$ ACC for 4 days followed by recovery for 7 days. The same results were observed for three independent experiments. Bar $=5 \mathrm{~cm}$. $\mathbf{b}$ Survival rate was determined after each treatment and recovery for 7 days. $B a r=5 \mathrm{~cm}$. The values are presented as mean \pm standard deviation based on 30 seedlings of each treatment obtained from six biologically independent experiments. ${ }^{*} P<0.05$ versus value at $0 \mu \mathrm{M}$ ACC treatment (Student's $t$ test)

on antioxidant enzyme activity under heat stress, we determined the activity of catalase (CAT), superoxide dismutase (SOD), ascorbate peroxidase (APX), and total peroxidase $(\mathrm{POX})$ in rice seedlings under heat stress with or without ACC treatment for 4 days. Our results showed that reductions in CAT and POX activity caused by heat stress were ameliorated by $10 \mu \mathrm{M}$ ACC treatment (Fig. 3b, e). Activity of APX was higher in the $10 \mu \mathrm{M}$ ACC treated rice seedlings than in the $0 \mu \mathrm{M}$ ACC treated and control seedlings (Fig. 3d). However, the activity of SOD presented no significant difference under heat stress with or without ACC treatment, but lower than control
Table 1 Chlorophyll concentration of rice seedlings under heat stress combined with ACC treatment

\begin{tabular}{|c|c|c|c|}
\hline \multirow{3}{*}{$\begin{array}{l}\text { Concentration } \\
\left(\mu \mathrm{g} \mathrm{g}^{-1} \mathrm{FW}\right)\end{array}$} & \multicolumn{3}{|l|}{ Treatment } \\
\hline & \multirow[t]{2}{*}{ Control } & \multicolumn{2}{|l|}{ Heat $\left(45^{\circ} \mathrm{C}\right)$} \\
\hline & & $0 \mu \mathrm{M} \mathrm{ACC}$ & $10 \mu \mathrm{M} \mathrm{ACC}$ \\
\hline Chlorophyll a & $0.627 \pm 0.081^{\mathrm{a},{ }^{*}}$ & $0.354 \pm 0.028^{c}$ & $0.433 \pm 0.010^{b}$ \\
\hline Chlorophyll b & $0.197 \pm 0.031^{\mathrm{a}}$ & $0.198 \pm 0.013^{\mathrm{a}}$ & $0.177 \pm 0.004^{a}$ \\
\hline Total chlorophyll & $0.833 \pm 0.113^{\mathrm{a}}$ & $0.558 \pm 0.017^{b}$ & $0.616 \pm 0.006^{b}$ \\
\hline Chlorophyll a/b ratio & $3.196 \pm 0.175^{\mathrm{a}}$ & $1.798 \pm 0.268^{c}$ & $2.448 \pm 0.109^{b}$ \\
\hline
\end{tabular}

The values are presented as mean \pm standard deviation based on six biologically independent experiments

${ }^{*}$ Different letters indicate significant difference between the treatments assessed using the LSD post hoc test $(P<0.05)$

seedlings (Fig. 3c). Our data showed that the ethylene precursor affected antioxidant enzyme activity under heat stress.

\section{Ethylene-mediated signaling enhanced $\mathrm{Hsf}$ and ethylene-related gene expression in rice seedlings under heat stress}

To clarify the effects of ethylene signaling on $H s f$ expression during heat stress, 12-day-old rice seedlings were treated with heat stress with or without $10 \mu \mathrm{M}$ ACC treatment for $1 \mathrm{~h}$ and then subjected to quantitative reverse transcriptase-polymerase chain reaction (RTPCR) to determine mRNA expression. The results indicated that in addition to $H s f A 2 b$, the induction levels of $H s f A 1 a, H s f A 2 a, c, d, e$, and $f$ were significantly higher in seedlings under heat stress with $10 \mu \mathrm{M}$ ACC treatment than in those under heat stress only (Fig. 4).

In the ethylene biosynthesis process, ACC oxidase, as an impotent enzyme, was catalyzed ACC into ethylene. The quantitative RT-PCR results showed the mRNA expression of ACC oxidase 1 (ACO1) and ACC oxidase 3 $(A C O 3)$ were significantly higher in seedlings under heat stress with $10 \mu \mathrm{M}$ ACC treatment than under heat stress only (Fig. 5a). The expression levels of EIN 2, EIN-like 1, and EIN-like 2 (OsEIN2, OsEIL1, and OsEIL2, respectively, involved in ethylene signaling) were significantly higher in seedlings under heat stress with $10 \mu \mathrm{M} \mathrm{ACC}$ treatment than in those under heat stress only (Fig. 5b). These results indicated that ethylene-mediated signaling affected expression of $H s f s$ and genes involved in ethylene biosynthesis and signaling in rice seedlings under heat stress.

\section{Discussion}

In plants, heat stress causes water deficit, cell dehydration, and reduced leaf expansion. The optimal temperature for rice growth is $28 / 22{ }^{\circ} \mathrm{C}$ (Prasad et al. 2006). 


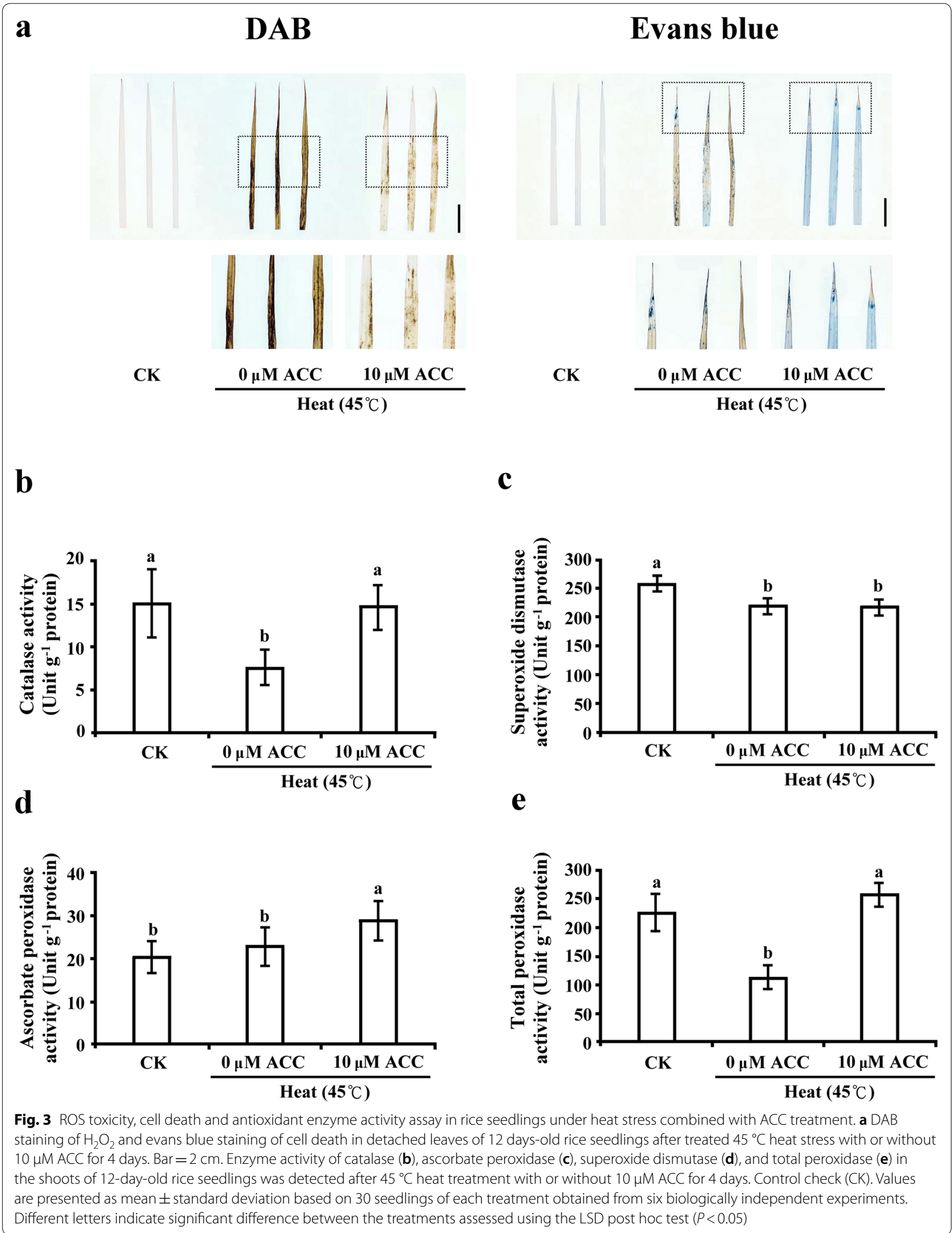




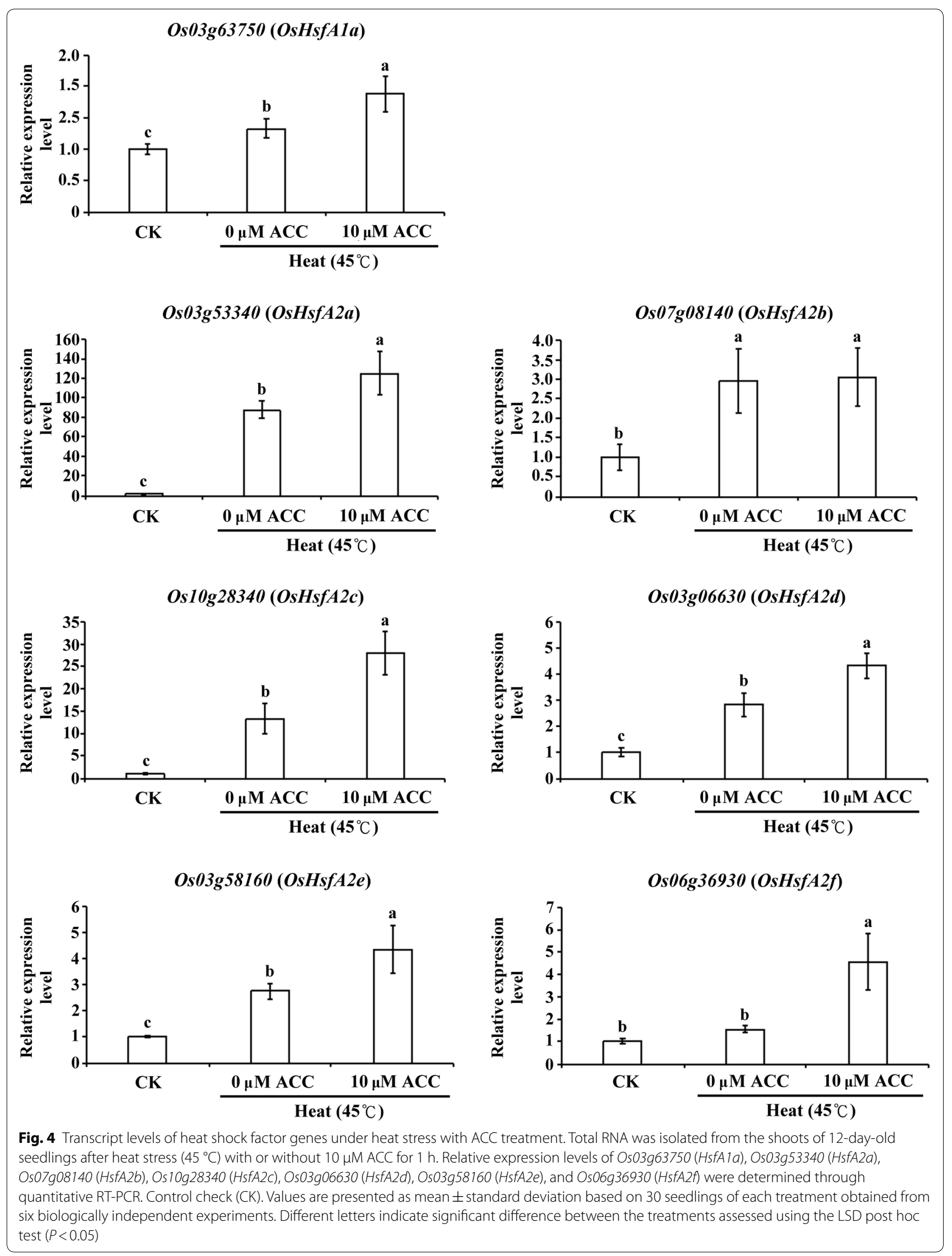




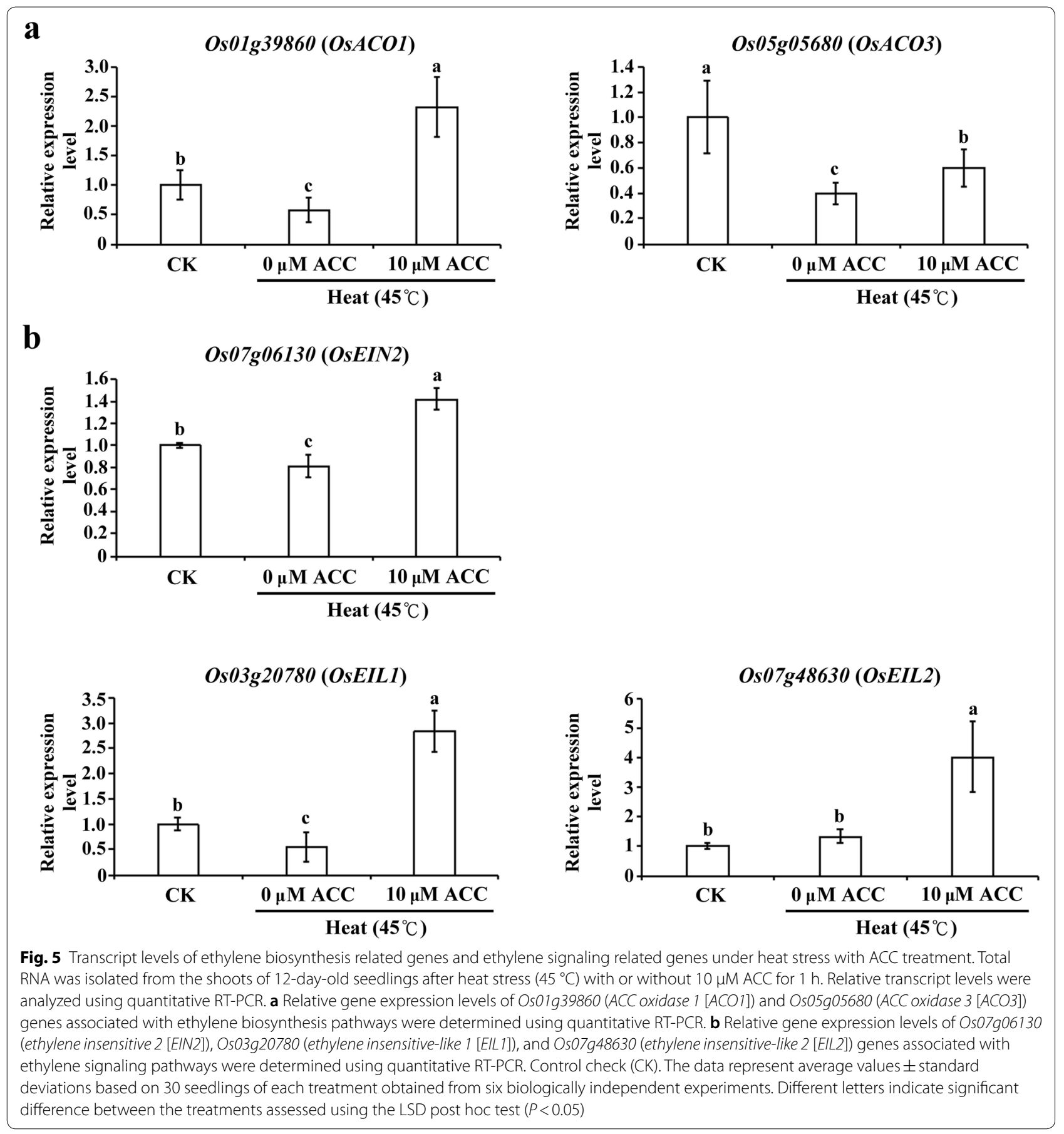

During reproductive processes, high temperature causes the failure of anther dehiscence, pollen grain germination on stigma, and pollen tube elongation, all of which lead to rice plant sterility and reduce rice yield (Satake and Yoshida 1978). Ethylene, a stress hormone, is involved in the regulation of many physiological properties. Studies have reported that ethylene is involved in the regulation of basal thermotolerance in Arabidopsis under heat stress (Larkindale and Knight 2002; Larkindale et al. 2005). Under normal condition, 12-day-old rice seedling did not show any difference phenotype between 0 and $10 \mu \mathrm{M}$ ACC treatment after treated for 4 days. In the present study, rice seedlings under heat stress with ACC treatment exhibited less yellowish and withered phenotype (Fig. 1a, b). The lipid oxidation of the cell membrane caused by heat stress was accompanied by electrolyte 
leakage (Liu and Huang 2000). However, in the present study, cell membrane stability was higher in rice seedlings with ethylene precursor treatment than in those under heat stress only. Studies have revealed lower oxidative damage and higher chlorophyll concentration in creeping bentgrass (Agrostis stolonifera var. palustris) upon pretreatment with the ethylene precursor ACC and subsequent exposure to heat stress (Larkindale and Huang 2004). In the present study, our results showed that the MDA concentration and electrolyte leakage were reduced by ethylene-mediated signaling in rice seedlings under heat stress with ACC treatment (Fig. 1c, d). Furthermore, we showed that heat stress combined with ACC treatment induced ethylene-mediated signaling, which resulted in higher survival rates in rice seedlings with the combination treatment than in seedlings under heat stress only (Fig. 2).

Chlorophyll a is the primary photosynthetic pigment that absorbs blue, red, and violet wavelengths in the visible spectrum. The primary function of chlorophyll $b$ is to complement the absorption spectrum of chlorophyll a by extending the range of light wavelengths (Bricaud et al. 1995). In a high-temperature environment, injury of the thylakoid membrane has been demonstrated to reduce chlorophyll content in rice and maize (Ristic et al. 2007). The chlorophyll $\mathrm{a} / \mathrm{b}$ ratio is associated with the photosynthesis capability of plants under biotic or abiotic stress. In this study, our results showed that ethylene-mediated signaling was involved in maintaining chlorophyll a content; thus, rice seedlings under heat stress and ACC treatment showed a higher chlorophyll $\mathrm{a} / \mathrm{b}$ ratio than did those under heat stress only (Table 1).

ROS such as hydrogen peroxide, hydroxyl radical, superoxide anion radicals, and singlet oxygen can be generated and accumulated in plants under heat stress (Suzuki et al. 2012). Uncontrolled ROS accumulation can damage a cell membrane, protein, and DNA and then cause programed cell death. The detoxification enzyme system is involved in the tolerance of plants under biotic and abiotic stress (Choudhury et al. 2017; Larkindale and Huang 2004). The results of the present study demonstrated that the enzyme activity of CAT, APX, and POX was enhanced by ACC treatment under heat stress (Fig. 3), and the findings confirmed that the ethylene signaling pathway can regulate scavenger enzymes to enable rice seedling adaptation under oxidative stress caused by high temperatures.

HsfA1s and HSFA2s play key roles in activating the heat stress transcription network (Ohama et al. 2017). Although studies have reported that the transcript levels of rice $H S F A 2 a, d$, and $e$ are upregulated under heat stress, little is known about the involvement of ethylenemediated signaling in the regulation of $H s f$ expression during heat stress (Cheng et al. 2013). In the current study, our results showed that the expression levels of $H S F A 1 a$ and $H S F A 2 a, c, d, e$, and $f$ were higher in rice seedlings under heat stress with ACC treatment than in those under heat stress only (Fig. 4). The genes expression was triggered at the related early stage compare with the phenotype change during stress. The study was shown that expression level of OsACO1 was no significant different in 14-day-old rice seedling under heat shock $40{ }^{\circ} \mathrm{C}$ for 90 min compared with control (Wilkins et al. 2016). In this study, our results showed the gene expression levels of OsACO1 and OsACO3 in 12-day-old rice seedlings under $45{ }^{\circ} \mathrm{C}$ for $1 \mathrm{~h}$ without ACC treatment was lower than control (Fig. 5). However, the expression of OsHsf $A 1$ and OsHsf $A 2$ genes were enhanced under $45{ }^{\circ} \mathrm{C}$ for $1 \mathrm{~h}$ without ACC treatment condition (Fig. 4). The results implied that the expression of OsHsfA1 and OsHsfA2 genes may regulated by complex signaling pathways during heat stress. One study depicted a model of the ethylene downstream signaling pathway, which indicated that the ethylene-mediated signaling was involved in maintaining the stay-green phenotype in Arabidopsis under heat stress (Abdelrahman et al. 2017). In the present study, we showed that expression of OsEIN2, OsEIL1, and OsEIL2 associated with ethylene signaling pathways was increased under heat stress with ACC treatment (Fig. 5). These data imply that ethylene-mediated signaling is involved in the expression of HSFs and downstream ethylene-signaling-related genes, thereby increasing the thermotolerance of rice seedlings.

Under heat stress, our study indicated the transcript level of ethylene biosynthesis gene and signal transduction associated gene were up-regulated and expanded the ethylene signal response via applied ethylene precursor under heat stress. The expression of HSFs gene was also up-regulated by ethylene-mediated signaling. We speculated the Hsfs triggering the antioxidant mechanism and reducing the oxidative damage during heat stress. Furthermore, the thermotolerance was enhanced and presented higher survival rate via ethylene-mediated signaling in rice seedling after heat stress.

\section{Conclusions}

In this study, our results suggest that ethylene-mediated signaling is involved in the maintenance of chlorophyll content, reduction of oxidative damage, and enhancement of thermotolerance in rice seedlings under heat stress. In addition, ethylene-mediated signaling regulates the mRNA transcripts of $H s f s$ and ethylene-signalingrelated genes during heat stress. This study provides key insights that clarify the interactions between ethylene and Hsfs that confer thermotolerance to rice seedlings. 


\section{Supplementary information}

Supplementary information accompanies this paper at https://doi. org/10.1186/s40529-019-0272-z.

Additional file 1: Table S1. The primer sequence used for quantitative RT-PCR in this study.

\section{Abbreviations}

ACC: 1-aminocyclopropane-1-carboxylic acid; APX: ascorbate peroxidase; CAT: catalase; HSF: heat shock factor; MDA: malondialdehyde; POX: total peroxidase; ROS: reactive oxygen species; RT-PCR: reverse transcriptase-polymerase chain reaction; SOD: superoxide dismutase.

\section{Acknowledgements}

Not applicable.

\section{Authors' contributions}

Y-SW carried out the experiments and analyzed the data. C-YY defined the research theme, designed experiments, and wrote the manuscript. Both authors read and approved the final manuscript.

\section{Funding}

This work was supported by the National Science Council, Taiwan, R.O.C. (NSC 101-2311-B-005-001) to Chin-Ying Yang.

\section{Availability of data and materials}

All data supporting the conclusions of this article are provided within the article (and its additional files).

\section{Ethics approval and consent to participate}

Not applicable.

\section{Consent for publication}

Authors agree to the terms of the Springer Open Copyright and License Agreement.

\section{Competing interests}

The authors declare that they have no competing interests.

Received: 27 April 2019 Accepted: 8 September 2019

Published online: 23 September 2019

\section{References}

Abdelrahman M, El-Sayed M, Jogaiah S, Burritt DJ, Tran L-SP (2017) The "STAYGREEN" trait and phytohormone signaling networks in plants under heat stress. Plant Cell Rep 36:1009-1025

Bradford MM (1976) A rapid and sensitive method for the quantitation of microgram quantities of protein utilizing the principle of protein-dye binding. Anal Biochem 72:248-254

Bricaud A, Babin M, Morel A, Claustre H (1995) Variability in the chlorophyllspecific absorption coefficients of natural phytoplankton: analysis and parameterization. J Geophy Res Oceans 100:13321-13332

Charng YY, Liu HC, Liu NY, Chi WT, Wang CN, Chang SH, Wang TT (2007) A heatinducible transcription factor, $\mathrm{HsfA2}$, is required for extension of acquired thermotolerance in Arabidopsis. Plant Physiol 143:251-262

Chauhan H, Khurana N, Agarwal P, Khurana P (2011) Heat shock factors in rice (Oryza sativa L.): genome-wide expression analysis during reproductive development and abiotic stress. Mol Genet Genomics 286:171

Cheng MC, Liao PM, Kuo WW, Lin TP (2013) The Arabidopsis ethyleneresponse-factor 1 regulates abiotic-stress-responsive gene expression by binding to different cis-acting elements in response to different stress signals. Plant Physiol 162:1566-1582

Choudhury FK, Rivero RM, Blumwald E, Mittler R (2017) Reactive oxygen species, abiotic stress and stress combination. Plant J 90:856-867

Djanaguiraman M, Prasad PV, Seppanen M (2010) Selenium protects sorghum leaves from oxidative damage under high temperature stress by enhancing antioxidant defense system. Plant Physiol Biochem 48:999-1007

Fang Y, Liao K, Du H, Xu Y, Song H, Li X, Xiong L (2015) A stress-responsive NAC transcription factor SNAC3 confers heat and drought tolerance through modulation of reactive oxygen species in rice. J Exp Bot 66(21):6803-6817

Guo J, Wu J, Ji Q, Wang C, Luo L, Yuan Y, Wang Y, Wang J (2008) Genome-wide analysis of heat shock transcription factor families in rice and Arabidopsis. J Genet Genomics 35:105-118

Guo M, Liu JH, Ma X, Luo DX, Gong ZH, Lu MH (2016) The plant heat stress transcription factors (HSFs): structure, regulation, and function in response to abiotic stresses. Front Plant Sci 7:114

Hong SW, Vierling E (2000) Mutants of Arabidopsis thaliana defective in the acquisition of tolerance to high temperature stress. Proc Natl Acad Sci 97:4392-4397

Jambunathan N (2010) Determination and detection of reactive oxygen species (ROS), lipid peroxidation, and electrolyte leakage in plants. Method Mol Biol 639:291-297

Kotak S, Larkindale J, Lee U, von Koskull-Döring P, Vierling E, Scharf KD (2007) Complexity of the heat stress response in plants. Curr Opin Plant Biol 10:310-316

Larkindale J, Huang B (2004) Thermotolerance and antioxidant systems in Agrostis stolonifera: involvement of salicylic acid, abscisic acid, calcium, hydrogen peroxide, and ethylene. J Plant Physiol 161:405-413

Larkindale J, Knight MR (2002) Protection against heat stress-induced oxidative damage in Arabidopsis involves calcium, abscisic acid, ethylene, and salicylic acid. Plant Physiol 128:682-695

Larkindale J, Hall JD, Knight MR, Vierling E (2005) Heat stress phenotypes of Arabidopsis mutants implicate multiple signaling pathways in the acquisition of thermotolerance. Plant Physiol 138:882-897

Liu HC, Charng YY (2012) Acquired thermotolerance independent of heat shock factor A1 (HsfA1), the master regulator of the heat stress response. Plant Signal Behav 7:547-550

Liu HC, Charng YY (2013) Common and distinct functions of Arabidopsis class $\mathrm{A} 1$ and $\mathrm{A} 2$ heat shock factors in diverse abiotic stress responses and development. Plant Physiol 163:276-290

Liu X, Huang B (2000) Heat stress injury in relation to membrane lipid peroxidation in creeping bentgrass. Crop Sci 40:503-510

Lohmann C, Eggers-Schumacher G, Wunderlich M, Schöffl F (2004) Two different heat shock transcription factors regulate immediate early expression of stress genes in Arabidopsis. Mol Genet Genomics 271:11-21

Maestri E, Klueva N, Perrotta C, Gulli M, Nguyen HT, Marmiroli N (2002) Molecular genetics of heat tolerance and heat shock proteins in cereals. Plant Mol Biol 48:667-681

Mangrauthia SK, Bhogireddy S, Agarwal S, Prasanth W, Voleti SR, Neelamraju S, Subrahmanyam D (2017) Genome-wide changes in microRNA expression during short and prolonged heat stress and recovery in contrasting rice cultivars. J Exp Bot 68(9):2399-2412

Müller M, Munné-Bosch S (2015) Ethylene response factors: a key regulatory hub in hormone and stress signaling. Plant Physiol 169:32-41

Nakano Y, Asada K (1981) Hydrogen peroxide is scavenged by ascorbate-specific peroxidase in spinach chloroplasts. Plant Cell Physiol 22:867-880

Ohama N, Sato H, Shinozaki K, Yamaguchi-Shinozaki K (2017) Transcriptional regulatory network of plant heat stress response. Trends Plant Sci 22:53-65

Prasad P, Boote K, Allen L Jr, Sheehy J, Thomas J (2006) Species, ecotype and cultivar differences in spikelet fertility and harvest index of rice in response to high temperature stress. Field Crops Res 95:398-411

Queitsch C, Hong SW, Vierling E, Lindquist S (2000) Heat shock protein 101 plays a crucial role in thermotolerance in Arabidopsis. Plant Cell 12:479-492

Ristic Z, Bukovnik U, Prasad PV (2007) Correlation between heat stability of thylakoid membranes and loss of chlorophyll in winter wheat under heat stress. Crop Sci 47:2067-2073

Sairam RK, Rao KV, Srivastava G (2002) Differential response of wheat genotypes to long term salinity stress in relation to oxidative stress, antioxidant activity and osmolyte concentration. Plant Sci 163:1037-1046

Satake T, Yoshida S (1978) High temperature-induced sterility in indica rices at flowering. Jpn J Crop Sci 47:6-17

Savada RP, Ozga JA, Jayasinghege CP, Waduthanthri KD, Reinecke DM (2017) Heat stress differentially modifies ethylene biosynthesis and signaling in pea floral and fruit tissues. Plant Mol Biol 95:313-331 
Scharf KD, Berberich T, Ebersberger I, Nover L (2012) The plant heat stress transcription factor (Hsf) family: structure, function and evolution. BBA Gene Regul Mech 1819:104-119

Schauberger B, Archontoulis S, Arneth A, Balkovic J, Ciais P, Deryng D, Elliott J, Folberth C, Khabarov N, Müller C (2017) Consistent negative response of US crops to high temperatures in observations and crop models. Nat Commun 8:13931

Schramm F, Ganguli A, Kiehlmann E, Englich G, Walch D, von Koskull-Döring $P$ (2006) The heat stress transcription factor HsfA2 serves as a regulatory amplifier of a subset of genes in the heat stress response in Arabidopsis. Plant Mol Biol 60:759-772

Shi H, Tan DX, Reiter RJ, Ye T, Yang F, Chan Z (2015) Melatonin induces class A1 heat-shock factors (HSFA1s) and their possible involvement of thermotolerance in Arabidopsis. J Pineal Res 58:335-342

Song L, Jiang Y, Zhao H, Hou M (2012) Acquired thermotolerance in plants. Plant Cell Tiss Organ Cult (PCTOC) 111:265-276

Suzuki N, Koussevitzky S, Mittler R, Miller G (2012) ROS and redox signalling in the response of plants to abiotic stress. Plant Cell Environ 35:259-270

von Koskull-Döring P, Scharf KD, Nover L (2007) The diversity of plant heat stress transcription factors. Trends Plant Sci 12:452-457

Wahid A, Gelani S, Ashraf M, Foolad MR (2007) Heat tolerance in plants: an overview. Environ Exp Bot 61:199-223

Wilkins O, Hafemeister C, Plessis A, Holloway-Phillips MM, Pham GM, Nicotra AB, Gregorio GB, Jagadish SK, Septiningsih EM, Bonneau R (2016) EGRINs (Environmental Gene Regulatory Influence Networks) in rice that function in the response to water deficit, high temperature, and agricultural environments. Plant Cell 28:2365-2384

Wu YS, Yang CY (2016) Physiological responses and expression profile of NADPH oxidase in rice (Oryza Sativa) seedlings under different levels of submergence. RICE 9:2

Yokotani N, Ichikawa T, Kondou Y, Matsui M, Hirochika H, Iwabuchi M, Oda K (2008) Expression of rice heat stress transcription factor OsHsfA2e enhances tolerance to environmental stresses in transgenic Arabidopsis. Planta 227:957-967

Yoshida S, Forno DA, Cock JA, Gomez KA (1976) Laboratory manual for plant physiological studies of Rice, 3rd edn. International Rice Research Institute, Manila

Yoshida T, Ohama N, Nakajima J, Kidokoro S, Mizoi J, Nakashima K, Maruyama K, Kim JM, Seki M, Todaka D (2011) Arabidopsis HsfA1 transcription factors function as the main positive regulators in heat shock-responsive gene expression. Mol Genet Genomics 286:321-332

Zhu X, Song F, Xu H (2010) Influence of arbuscular mycorrhiza on lipid peroxidation and antioxidant enzyme activity of maize plants under temperature stress. Mycorrhiza 20:325-332. https://doi. org/10.1130/0016-7606(1988)100\&lt;1666:SSF\&gt;2.3.CO;2

\section{Publisher's Note}

Springer Nature remains neutral with regard to jurisdictional claims in published maps and institutional affiliations.

\section{Submit your manuscript to a SpringerOpen ${ }^{\circ}$ journal and benefit from:}

- Convenient online submission

- Rigorous peer review

- Open access: articles freely available online

- High visibility within the field

- Retaining the copyright to your article

Submit your next manuscript at springeropen.com 